\title{
Preparation and Properties of Piezoelectric Lead Zirconate Titanate Thin Films for Microsensors and Microactuators by Sol-Gel Processing
}

\author{
Toshiyuki TUCHIYA ${ }^{\dagger}$, Toshihiro ITOH, Gen SASAKI ${ }^{\dagger \dagger}$ and Tadatomo SUGA \\ Research Center for Advanced Science and Technology, The University of Tokyo, 4-6-1, Komaba, Meguro-ku, Tokyo 153 \\ ゾル-ゲル法によるマイクロセンサー, マイクロアクチュエーター用圧電体 \\ チタン酸ジルコン酸鉛セラミックス薄膜の作製とその特性 \\ 土屋智由 + 伊藤寿浩・佐々木 元 $^{\dagger \dagger} \cdot$ 須賀唯知 \\ 東京大学先端科学技術研究センター, 153 東京都目黒区駒場 4-6-1
}

\begin{abstract}
Crack-free ferroelectric thin films of lead zirconate titanate $\left(\mathrm{PbZr}_{x} \mathrm{Ti}_{1-x} \mathrm{O}_{3} ; \mathrm{PZT}\right)$ for microsensors and microactuators have been prepared by sol-gel processing. Lead acetate, zirconium butoxide, and titanium isopropoxide were used as precursors, acetic acid as the solvent and ethylene glycol as an additive. Films of up to $3.1 \mu \mathrm{m}$ thick were prepared by a spin-coating and multiple coating technique. The stoichiometric microstructure of the film separated into islandlike perovskite regions and interconnected amorphous and/or nanocrystalline regions. Films with a $\mathbf{P b}$ concentration greater than $20 \%$ have only perovskite regions. The dielectric constant of these films is 1800 . The spontaneous polarization, the remnant polarization and the coercive field are $39.2 \times 10^{-2} \mathrm{C} / \mathrm{m}^{2}, 18.4 \times 10^{-2} \mathrm{C} / \mathrm{m}^{2}$ and $59.9 \times$ $10^{5} \mathrm{~V} / \mathrm{m}$, respectively. Aiming at the application of piezoelectric thin films to microsensors and microactuators, we fabricated a PZT diaphragm by anisotropic etching of silicon. The Young's modulus, residual stress and piezoelectric coefficient $d_{31}$ were measured as 91.2 GPa, $-2.0 \mathrm{MPa}$ and $30.0 \times$ $10^{-12} \mathrm{C} / \mathrm{N}$, respectively, from its deflection and piezoelectric output.
\end{abstract}

[Received July 6, 1995; Accepted November 13, 1995]

Key-words : PZT, Sol-gel processing, Thin film, Microsensor, Microactuator, Crack-free films, Piezoelectric properties

1. Introduction

Recently, much improved LSI process technology has led to processing techniques for very small mechanical elements. "Micromachines" can be assembled from these elements, and have the potential to be developed into new sensors and actuators. The piezoelectric effect suitable for these applications, and piezoelectric thin films are of great interest.

Lead zirconate titanate $\left(\mathrm{PbZr}_{x} \mathrm{Ti}_{1-x} \mathrm{O}_{3} ; \mathrm{PZT}\right)$ has a perovskite structure and shows ferroelectricity. Near the morphotropic phase boundary (MPB) composition $(x=0.53)$, it has a large dielectric constant and exhibits the piezoelectric effect.

In order to use a ferroelectric material in microsensors and microactuators, ferroelectric thin films must be fabricated on substrates. These films have been fabricated by various methods including $\mathrm{rf}$ sputtering, ${ }^{1,2)}$ ion beam sputtering, ${ }^{3)}$ and EB evaporation. $\left.{ }^{4}\right) \mathrm{Paz}$ de Araujo et al. investigated ferroelectric thin films as possible capacitor films in semiconductor memories. ${ }^{5)}$

\footnotetext{
${ }^{\dagger}$ Present address: Toyota Central R \& D Laboratories Inc., Nagakute-cho, Aichi $480-11$

現在：(株)豊田中央研究所, 480-11 愛知県愛知郡長久手町

† Present address: Faculty of Engineering, Hiroshima University, 1-4-1, Kagamiyama, Higashi-Hiroshima-shi 739 現在 : 広島大学工学部第 1 類, 739 広島県東広島市鏡山 $1-$ $4-1$
}

Sol-gel processing of complex oxide systems has many advantages: (1) low-temperature annealing process, (2) homogeneity of coating solution, (3) easy control of composition and (4) simplicity. Many fabrication methods have been reported and good ferroelectric properties have been obtained.6)-9) However, these films were so thin for the transducers that their piezoelectric properties and mechanical properties could not be evaluated as deposited on the substrates. It is necessary to fabricate a suitable measuring device.

In this study, thick PZT films for microsensor and microactuator application were prepared by sol-gel processing. The dependence on the processing conditions is the main subject of investigation. A piezoelectric thin film diaphragm was fabricated by micromachining and its electric, mechanical and piezoelectric properties were measured. Then, its potential for microsensor application was evaluated.

\section{Experimental procedure}

Lead acetate trihydrate, zirconium $n$-butoxide $(2.047 \mathrm{~mol} / \mathrm{kg}$ butanol solution) and titanium tetraisopropoxide were used as precursors. The preparation method for the films used in this study was similar to that originally reported by Yi et al. ${ }^{9)}$

Lead acetate is dissolved in acetic acid and dehydrates at $105^{\circ} \mathrm{C}$. Zirconium butoxide and titanium 


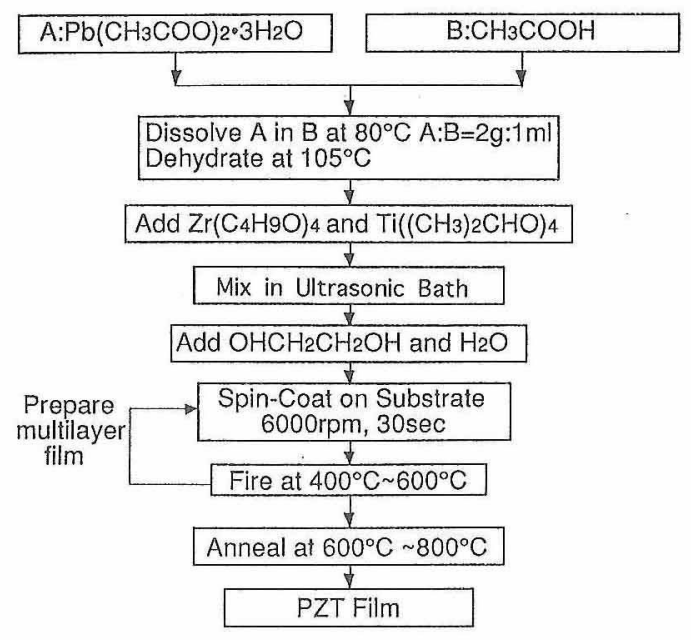

Fig. 1. Flow diagram for sol-gel processing of PZT films.

isopropoxide were added after cooling to below $80^{\circ} \mathrm{C}$ and the precursors were blended in an ultrasonic bath. Ethylene glycol and distilled water were then added. The substrate used was an oxidized silicon wafer coated with platinum and titanium by electron beam (EB) deposition. The substrate is made up of $(\mathrm{PZT}) / \mathrm{Pt} / \mathrm{Ti} / \mathrm{SiO}_{2} / \mathrm{Si}$, and the thicknesses of $\mathrm{Pt} / \mathrm{Ti}$, $\mathrm{SiO}_{2}$ and $\mathrm{Si}$ are $0.2,1.8$ and $390 \mu \mathrm{m}$, respectively. Titanium evaporation improves the bond strength between the platinum and the wafer. The solution was then spin-coated and fired at $400-600^{\circ} \mathrm{C}$ for $20 \mathrm{~min}$. The spin-coating and firing were repeated so until the desired thickness was obtained. Then the films were annealed at $600^{\circ} \mathrm{C}$ for $6 \mathrm{~h}$. The flow diagram for the film preparation is shown in Fig. 1.

The thickness of the films was measured using a surface profile meter (Sloan Dektak IIAV). The microstructure was observed using a scanning electron microscope (SEM) and a transmission electron microscope (TEM). The crystal structure was determined by X-ray diffraction (XRD) and the TEM electron diffraction image. The chemical composition of the films was measured by a qualitative electron dispersive spectroscopy (EDS) using the SEM.

The dielectric properties were measured using a function generator (NF 1920A) and a lock-in amplifier (NF 5610B) at $1 \mathrm{kHz}$, and the ferroelectric properties were measured using a Sawyer-Tower circuit at $50 \mathrm{~Hz}$ and $1 \mathrm{kHz}$. A gold/chromium electrode was deposited on both surfaces of the specimen for these measurements by a vacuum evaporation.

The mechanical and piezoelectric properties were measured by deflecting a diaphragm consisting of the PZT film, electrodes and supporting film. Figure 2 shows the diaphragm structure. The diaphragm was fixed on a stand. By evaculating from the under side in Fig. 2, we deflected the diaphragm. The degree of deflection was calculated from the number of interference rings formed in the reflected beam of a He-Ne laser. The applied pressure was measured using a vacuum guage. Analysis of the

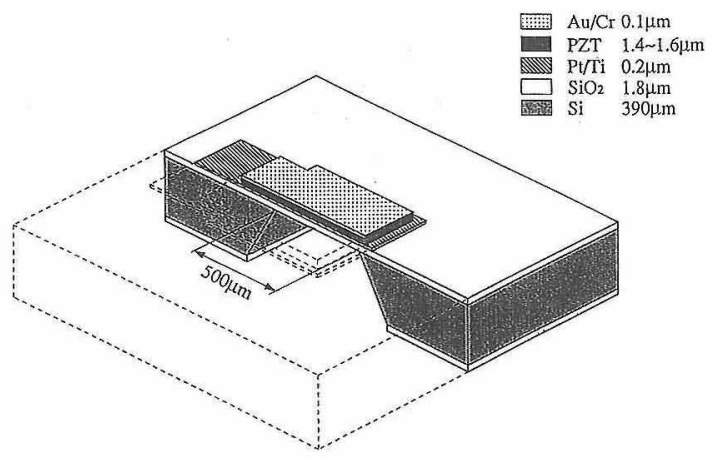

Fig. 2. Thin film diaphragm fabricated using PZT film for measuring the mechanical and piezoelectric properties.

load deflection behavior of the film using the principle of imaginary work corresponding to the elastic deformation energy, but modified to account for the presence of internal stress, leads to the following relation: ${ }^{10)}$

$$
\left(\frac{Y t}{a_{4}}\right) W_{\mathrm{o}}^{3}+\left(\frac{1.66 \sigma_{\mathrm{r}} t}{a_{2}}\right) W_{\mathrm{o}}=0.547 p
$$

where $p$ is the applied pressure, $Y$ is Young's modulus, $\sigma_{\mathrm{r}}$ is the internal stress, $2 a$ is the site size of a square PZT film, $t$ is the film thickness, and $W_{\mathrm{o}}$ is the deflection at the film center. By measuring the applied pressure and the film deflection, we calculated Young's modulus and the internal stress.

The electric displacement generated by producing a strain in the film is expressed as

$$
D_{\mathrm{s}}=d_{31} Y\left(S_{1}+S_{2}\right) /(1-v)
$$

where $D_{\mathrm{s}}$ is the electric displacement, $d_{31}$ is the piezoelectric constant, $S_{1}$ and $S_{2}$ are the stresses along the $x$ and $y$ directions, respectively, and $v$ is Poisson's ratio.

The electric charge is obtained by integrating Eq. (2) over the whole area:

$$
Q=\pi^{2} Y d_{31} W_{0}^{2} / 4
$$

where $Q$ is the electric charge, and $W_{\mathrm{o}}$ is the deflection along the $z$ direction at the film center.

The piezoelectric constant $d_{31}$ is obtained by substituting the output potential $(Q)$ and the film deflection $\left(W_{0}\right)$ into Eq. (3). Q and $W_{0}$ are measured after polarizing perpendicular to the $z$ direction.

Young's modulus and the internal stresses were calculated from the center displacement when pressure was applied. The piezoelectric constant $d_{31}$ was caluculated from the piezoelectric output of the deflected diaphragm. Details of these measurements will be reported elsewhere. ${ }^{11)}$

\section{Results and discussions}

PZT films for microsensors and microactuators must have good piezoelectric properties, be crackfree, and have a thickness of about $0.5-5 \mu \mathrm{m}$. In order to obtain a thick film by a single coating and firing, the spin-coating speed and the viscosity of the solution were controlled. In the case of single-layer PZT 
films, crack-free transparent films were prepared by firing at $400^{\circ} \mathrm{C}$. However in deposited films of up to $0.4 \mu \mathrm{m}$, cracks occurred. In order to obtain a crackfree thick film, the multiple coating and high-temperature firing treatments which were carried out at higher temperatures than that of the general treatment (about $400^{\circ} \mathrm{C}$ ) were attempted. Spin-coating and the firing at $600^{\circ} \mathrm{C}$ were repeated until the thickness was $3.1 \mu \mathrm{m}$. The thick films began to show translucence at thicknesses greater than $1 \mu \mathrm{m}$.

$\mathrm{Yi}$ et al. ${ }^{9)}$ divided the firing process into three steps: (1) solvent evaporation $\left(\sim 250^{\circ} \mathrm{C}\right)$, (2) lead acetate dehydration, melting, and decomposition, (3) free carbon oxidization and transformation to an amorphous PZT film. The internal stress in the film is caused by compression relaxation in the second step. The film may crack at the first step. In the high-temperature firing process, the first two steps occur very fast and successively. Therefore the stress relaxes without causing cracking.

Figure 3 shows XRD patterns of films annealed at various temperatures. After annealing at 600 and $700^{\circ} \mathrm{C}$, the films crystallized with a purely perovskite structure. In the X-ray pattern of the PZT film annealed at $800^{\circ} \mathrm{C}$, the perovskite structure peaks broadened. This indicates $\mathrm{Pb}$ evaporation a form of $\mathrm{PbO}$ at $800^{\circ} \mathrm{C}$.

Figure 4 shows the microstructure of the film annealed at $600^{\circ} \mathrm{C}$ observed by SEM. The films prepared from a solution with a composition equal to the MPB composition are divided into two regions. The white regions (symbol (A)) are circular, about 0.5$1 \mu \mathrm{m}$ in diameter and islandlike in appearance. The black regions (symbol (B)) surround among the white regions.

Figure 5 shows a TEM micrograph of the film annealed at $600^{\circ} \mathrm{C}$. The microstructure of the film consists of two regions, like that shown in Fig. 4. However, the black-white contrast of the TEM image is the reverse of the SEM image. The dark islandlike regions observed in Fig. 5 correspond to the white regions in Fig. 4. Transmission electron

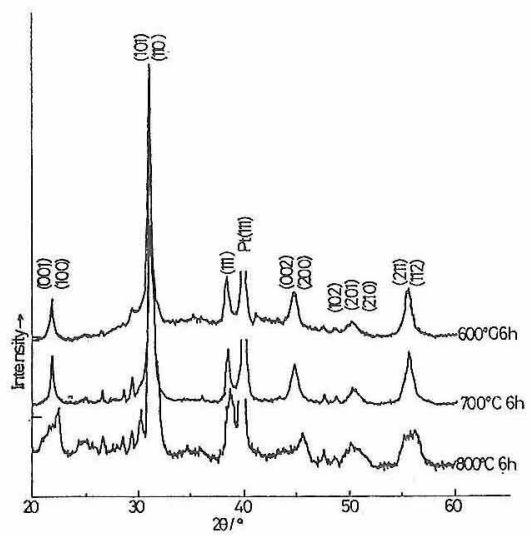

Fig. 3. XRD patterns for the PZT film as a function of annealing time at 600,700 and $800^{\circ} \mathrm{C}$, respectively.

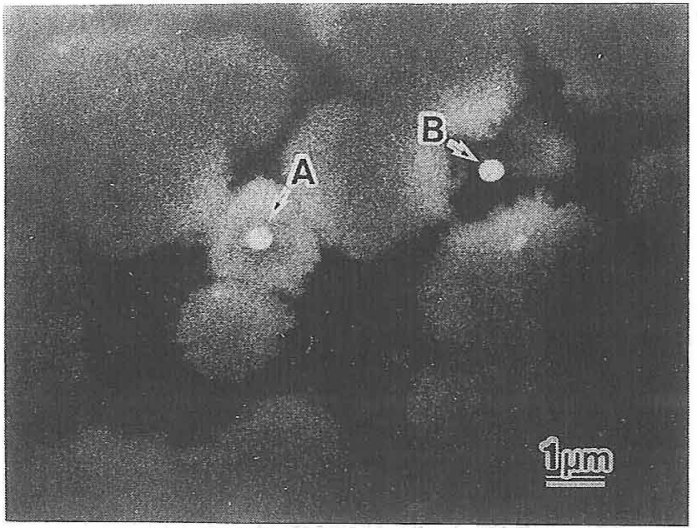

Fig. 4. Microstructure of PZT film annealed at $600^{\circ} \mathrm{C}$ observed by SEM. Symbols A and B indicate the islandlike white region and the black region, respectively.

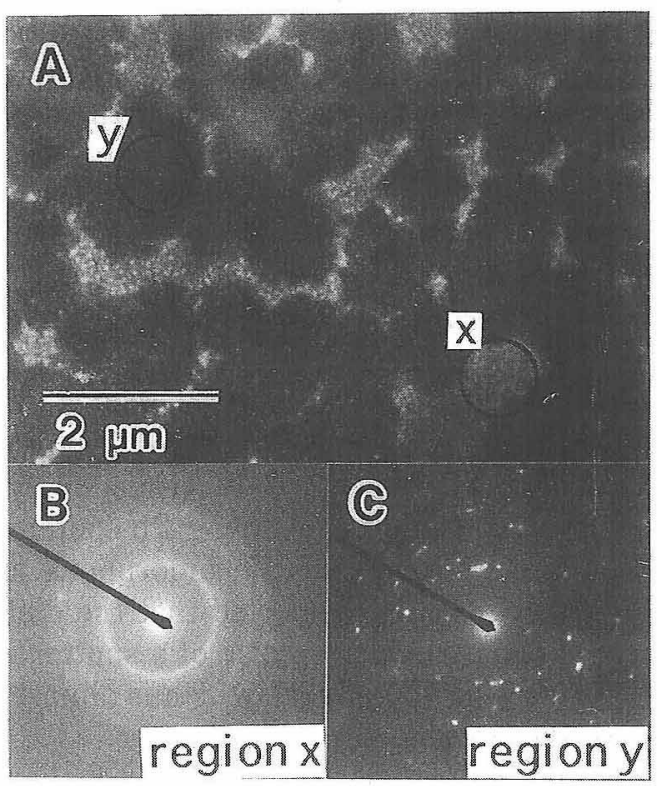

Fig. 5. TEM micrographs of the PZT film. (A) shows the microsturcture of PZT. Symbols $x$ and $y$ indicate a bright region and dark region, respectively. (B) and (C) show diffraction patterns from region $x$ and region $y$ in (A), respectively.

diffraction (Fig. 5(C)) shows that the islandlike regions are polycrystals with a perovskite structure. From high-resolution observation, the grain of the perovskite structure is equiaxed and $50-60 \mathrm{~nm}$ in diameter. The bright regions are amorphous and/or nanocrystals (Fig. $5(\mathrm{~B})$ ).

The compositions of these two regions are different. The perovskite phase has a similar composition to the coating solution. The amorphous and/or nanocrystal region, however, is significantly different, and has a low $\mathrm{Pb}$ content $(\mathrm{Pb}: \mathrm{Zr}: \mathrm{Ti}=6: 5: 4)$. Carim et $\mathrm{al}^{12}{ }^{12}$ reported that this region is a paraelectric pyrochlore phase, and the lack of $\mathrm{Pb}$ prevents the formation of the perovskite phase. However, in this study, the pyrochlore phase was not observed in the electron diffraction pattern obtained from the amorphous and/or nanocrystal region, which shows 
ring patterns, the lattice spacings of which agree with those of the perovskite phase. The films prepared using a coating solution with excess $\mathrm{Pb}$ content had improved phase separations.

Figure 6 shows the dependence of the composition of the films on the excess $\mathrm{Pb}$ content, which approaches that of the polycrystal region with increasing $\mathrm{Pb}$ content. The polycrystal region may expand with increasing $\mathrm{Pb}$ content. The film with $20 \mathrm{~mol} \%$ excess $\mathrm{Pb}$ content has no amorphous or nanocrystal region and the composition of the whole film is similar to the MPB composition, as shown in Fig. 6. The reason why $\mathrm{Pb}$ is evaporated is not clear. Lakeman and Payne ${ }^{13)}$ reported that an ester produced during the preparation of the coating solution prevents films from crystallizing with a perovskite structure. In our process, an ester may be produced, but it cannot explain the composition of the pyrochlore region. Therefore it is considered that $\mathrm{Pb}$ evaporation occurs during the preparation process. Annealing below $700^{\circ} \mathrm{C}$ does not have any effect on the structure of the films, and so the evaporation may occur during the firing process.

The dependence of the dielectric constants of the films on excess $\mathrm{Pb}$ content is shown in Fig. 7. As the $\mathrm{Pb}$ content increases, the dieletric constant increases gradually. The dielectric constant $\varepsilon_{\mathrm{r}}$, spontaneous polarization $P_{\mathrm{s}}$ and piezoelectric constant $d_{31}$ for the 20 mol\% excess $\mathrm{Pb}$ content film are $1800,39.2 \times$ $10^{-2} \mathrm{C} / \mathrm{m}^{2}$ and $30.0 \times 10^{-12} \mathrm{C} / \mathrm{N}$, respectively. The low dielectric constant of the lower $\mathrm{Pb}$ content films is due to the existence of the amorphous and/or nanocrystal region. It is reported that the dielectric constant of the pyrochlore phase of a sputtered thin film is $20(\mathrm{Zr}: \mathrm{Ti}=50: 50),{ }^{2)}$ which is almost equal to that of the present film.

All films have ferroelectricity. Figure 8 shows the $P-E$ hysteresis loop of the film containing $20 \mathrm{~mol} \%$ excess $\mathrm{Pb}$. The spontaneous polarization $P_{\mathrm{s}}$ is $39.2 \times$ $10^{-2} \mathrm{C} / \mathrm{m}^{2}$, the remnant polarization $P_{\mathrm{r}}$ is $18.4 \times$ $10^{-2} \mathrm{C} / \mathrm{m}^{2}$ and the coercive field $E_{\mathrm{c}}$ is $59.9 \times 10^{5} \mathrm{~V} /$ $\mathrm{m}$. These values are similar to those of PZT thin films fabricated using various methods. The remnant polarization is slightly lower, and the coercive field is much higher than those bulk of PZT ceramics. This is due to the small grain size of the films. The spontaneous polarization in relation to the excess $\mathrm{Pb}$ content is shown in Fig. 7. The amorphous and/or nanocrystal region reduces the polarization of the film. However, the coercive field of the film has no apparent dependence on the $\mathrm{Pb}$ content, and so the ferroelectric properties of the perovskite regions seem to be the same in all of these films.

Young's modulus and the internal stress of the diaphragm fabricated using the film containing 20 mol\% excess $\mathrm{Pb}$ are $91.2 \mathrm{GPa}$ and $-2.0 \mathrm{MPa}$, respectively. Considering the multilayer effect of the components of the diaphragm, the Young's modulus of the PZT film is $101 \mathrm{GPa}$. This value is slightly higher than that of the bulk ceramics because of its dense structure. When we fabricate a thin film diaphragm or cantilever, we must control the internal stress of the film. The internal stress of thermal $\mathrm{SiO}_{2}$ film is $-310--340 \mathrm{MPa}$ (oxidized at $1200^{\circ} \mathrm{C}$ ). ${ }^{14)}$ The internal stress of the PZT film is tensile because of the loss of volume during firing and the large thermal expansion coefficient (PZT : $6.1 \times 10^{-6} / \mathrm{K}, \mathrm{Si}$ : $\left.0.4 \times 10^{-6} / \mathrm{K}, \mathrm{SiO}_{2}: 2.4 \times 10^{-6} / \mathrm{K}\right)$. Since these internal stresses are balanced, the thin film diaphragms were not broken.

The piezoelectric coefficient $d_{31}$ is $46.5 \times 10^{-12} \mathrm{C} /$ $\mathrm{N}$, which is equivalent to that of bulk PZT ceramics of grain size $0.6 \mu \mathrm{m} .{ }^{15)}$ The perovskite phase region separated from the region with no excess $\mathrm{Pb}$ has grains $0.5-1 \mu \mathrm{m}$ in size, and so the film with 20 mol\% excess $\mathrm{Pb}$ may have similar grain size. Its dependence on the excess $\mathrm{Pb}$ content is also shown in Fig. 7.

\section{Summary}

PZT thin films for microsensors and microactuators were prepared from lead acetate and zirconium,

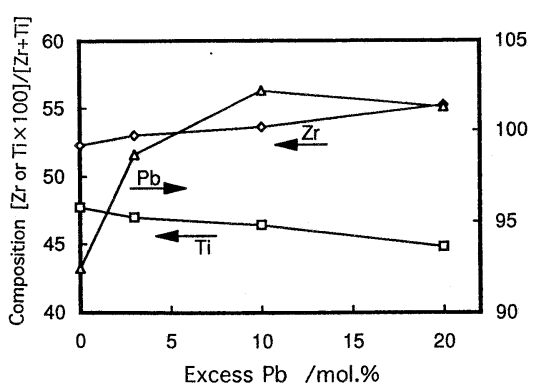

Fig. 6

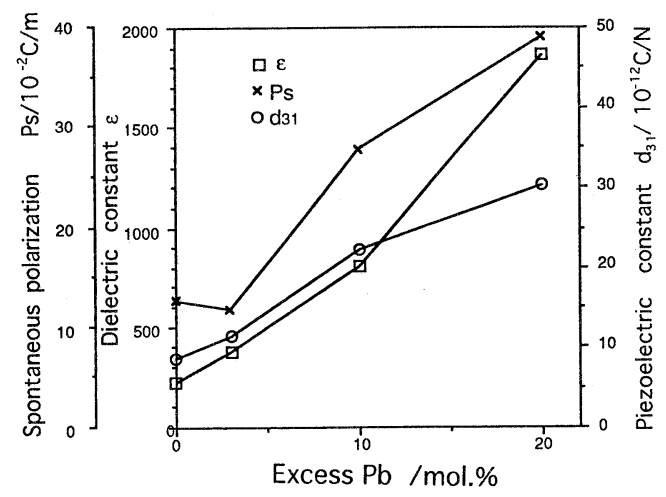

Fig. 7

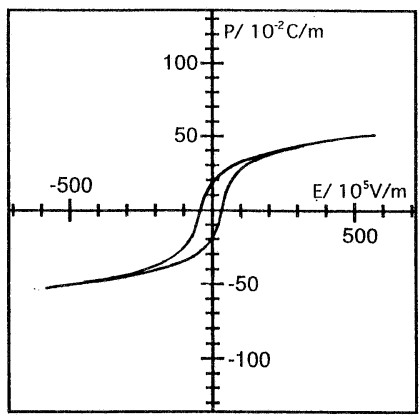

Fig. 8

Fig. 6. Composition of PZT films as a function of excess $\mathrm{Pb}$ content, which is $0,3,10$ and $20 \mathrm{~mol} \%$.

Fig. 7. Dielectric, ferroelectric and piezoelectric properties of the PZT films as a function of Pb content, which is $0,3,10$ and $20 \mathrm{~mol} \%$.

Fig. 8. $P-E$ hysteresis loop for a PZT film. 
titanium alkoxide solution by sol-gel processing. High-performance, crack-free, thin $(3.1 \mu \mathrm{m})$ films were acquired by multiple coating, and high-temperture annealing.

$\mathrm{PbO}$ evaporation occurred on firing. This is caused by the lack of $\mathrm{Pb}$ and the structure is divided into a perovskite phase and the amorphous and/or nanocrystal regions. The existence of the amorphous and/or nanocrystal region reduces the dielectric and piezoelectric constants. Excess $\mathrm{Pb}$ diminishes the amorphous and/or nanocrystal region and improves the piezoelectric and ferroelectric properties.

A $20 \mathrm{~mol} \% \mathrm{~Pb}$ excess PZT film has good piezoelectric properties. The dielectric constant $\varepsilon_{\mathrm{r}}$, the piezoelectric constant $d_{31}$ and the spontaneous polarization $P_{\mathrm{s}}$ are $1800,30.0 \times 10^{-2} \mathrm{C} / \mathrm{m}^{2}$ and $39.2 \times 10^{-12}$ $\mathrm{C} / \mathrm{N}$, respectively. These values are similar to those of bulk PZT ceramics. This PZT film will be used in the fabrication of microactuators and microsensors.

Acknowledgments This research was supported by a Grantin-Aid from the Ministry of Education, Science and Culture, No. 05555020 .

\section{References}

1) A. Okada, J. Appl. Phys., 49, 4495-99 (1978).

2) S. B. Krupanidhi, N. Maffei, M. Sayer and K. El-Assal, $J$. Appl. Phys., 54, 6601-09 (1983).

3) R. N. Castellano and L. G. Feinstein, J. Appl. Phys., 50, 4406-11 (1979).

4) M. Oikawa and K. Toda, Appl. Phys. Lett., 29, 49192(1976).

5) C. A. Paz de Araujo, L. D. McMillan, B. M. Melnick, J. D. Cuchiaro and J. F. Scott, Ferroelectrics, 104, 241-56 (1990).

6) Y. Takahashi, Y. Matsuoka, K. Yamaguchi, M. Matsuki and K. Kobayashi, J. Mater. Sci., 25, 3960-64 (1990).

7) N. Tohge, S. Takahashi and T. Minami, J. Am. Ceram. Soc., 74, 67-71 (1991).

8) K. D. Budd, S. K. Dey and D. A. Payne, Br. Ceram. Proc., 36, 107-21 (1985).

9) G. Yi, Z. Wu and M. Sayer, J. Appl. Phys., 64, 2717-24 (1988).

10) S. P. Timoshenko and S. W.-Kriger, "Theory of Plates and Shells", McGraw-Hill (1959).

11) T. Tsuchiya, T. Itoh and T. Suga (unpublished).

12) A. H. Carim, B. A. Tuttle, D. H. Doughty and S. L. Martinez, J. Am. Ceram. Soc., 74, 1455-58 (1991).

13) C. D. E. Lakeman and D. A. Payne, J. Am. Ceram. Soc., 75, 3091-96 (1992).

14) R. J. Jaccodine and W. A. Schlegel, J. Appl. Phys., 37, 2429-34 (1966).

15) K. Okazaki and K. Nagata, J. Am. Ceram. Soc., 56, 82-86 (1973). 